\title{
NotAs SOBRe CONCEPCión ARENAL
}

\author{
Carmen RUIDÍAZ GARCÍA \\ DOCTORA EN CIENCIAS POLÍTICAS Y SOCIOLOGÍA \\ PROFESORA TITULAR INTERINA DE TRABAJO SOCIAL \\ UNIVERSIDAD DE LA RIOJA
}

SUMARIO: I. Introducción. II. Concepción Arenal (I820-I893): una mujer de acción y una intelectual comprometida con su tiempo. III. Sus obras. Un legado histórico. III.I. Cartas a los delincuentes. III.2. Estudios penitenciarios. IV. A modo de conclusión. V. Bibliografía.

RESUMEN: La figura de Concepción Arenal, cuando se la estudia, aparece casi siempre vinculada al Derecho Penal, a las prisiones, al preso. Fue como penalista, como reformadora de prisiones y como estudiosa de la psicología del preso y de su entorno social como su fama se consolidó, traspasó nuestras fronteras y alcanzó la cima, pero su personalidad era tan polifacética que no dejó tema sin analizar, ni problema social sin abordar. Puede decirse que, en el siglo XIX, Concepción Arenal, con su inteligencia y con su pluma, iluminó los más oscuros rincones donde se escondían la injusticia, la pobreza, la violencia, la tiranía, la discriminación, los privilegios de clase y de género, denunciando muy especialmente la inhumana situación de los presos.

PALABRAS ClAVE: Derecho penal, prisiones, presos, discriminación, problemas sociales.

TITLE: Some Notes about Concepción Arenal.

ABSTRACT: When Concepción Arenal is studied, she is almost always linked to Criminal Law, prisons and prisoners. She became more renown, crossed over the Spanish borders and went straight to the top as a criminal lawyer, a prison reformer and an expert in the psychology of prisoners and their social environment. Her personality was so versatile that she did not leave any subject unanalyzed, or any social problem uncovered. It can be said that, in the igth century, Concepción Arenal, with her intelligence and her pen, enlightened the darkest corners where injustice, poverty, violence, tyranny, discrimination, class and gender privileges were hiding, while most importantly condemning the inhumane situation of prisoners.

KEYWORDS: Criminal law, prisons, prisoners, discrimination, social problems. 


\section{Introducción}

Detrás de las reformas de las instituciones jurídico-penales existen personas que las inspiran. El espíritu de los pioneros que consiguieron en buena lid impulsar cambios pervive con los mismos. Por ello resulta interesante (e imprescindible) volver al pasado para encontrarnos con Concepción Arenal, una mujer que con mirada fresca nos enseño, y nos sigue enseñando, a comprender, entre otros aspectos, el delito, los delincuentes, las prisiones. ${ }^{\text {I }} \mathrm{Su}$ obras, su vida, nos hablan de un espíritu inquebrantable y un profundo compromiso humano y social.

\section{Concepción Arenal (I820-I893): una mujer de acción y una intelectual comprometida con su tiempo}

Conviene empezar diciendo que aunque algunos libros históricos nos relatan con gran precisión los trabajos de Concepción Arenal y los resultados de su labor, ${ }^{2}$ con escasas excepciones nos aportan un cuadro sobre la personalidad individual. Ella misma, celosa de su intimidad, se negaba a facilitar datos alegando que no le gustaba hablar de ella. ${ }^{3}$

Pese a todo, hoy podemos afirmar que fue una polifacética mujer, inteligente y osada, prudente, responsable y equilibrada, al mismo tiempo que sencilla, sincera e independiente, tanto en su modo de pensar como en el de actuar.

De sus raíces familiares decir que el padre ${ }^{4}$ de Concepción Arenal, militar ilustrado, se posicionó al lado de la Constitución y la creación del Estado liberal, una persona que mostraba una fina sensibilidad humanista y un fuerte sentido del honor. ${ }^{5}$

\footnotetext{
${ }^{1}$ La compilación de sus escritos fueron publicados en I909 por la Editorial Vizcaína de Bilbao, reeditados en I934 por la editorial Tip Huelves y Cia de Madrid.

Contenido de las Obras completas de de Concepción Arenal: Tomo I. El visitador del pobre. Tomo 2. La beneficencia, la filantropía y la caridad. Tomo 3. Cartas a los delincuentes. Tomo 4. La mujer del porvenir y la mujer de su casa. Tomo 5. Estudios penitenciarios I. Tomo 6. Estudios penitenciarios II. Tomo 7. La cuestión social: cartas a un obrero. Tomo 8. La cuestión social: cartas a un señor. Tomo 9. Ensayo sobre el Derecho de gentes. Tomo io. Las colonias penales de la Australia y la pena de deportación. A todos. Examen de las Bases aprobadas por las Cortes para la Reforma de Prisiones y la cárcel llamada Modelo. Tomo ir. La instrucción del pueblo. Observaciones sobre la educación física, intelectual y moral de Herbert Spencer. La instrucción del obrero y la educación de la mujer. Tomo I2. El derecho de gracia ante la justicia. El reo, el pueblo y el verdugo o la ejecución pública de la pena de muerte y el delito colectivo. Tomo I3. El visitador del preso. Tomo I4. Informes presentados en los Congresos penitenciarios de Estocolmo, Roma, San Petersburgo y Amberes. Tomo I5. El pauperismo I. Tomo I6. El pauperismo II. Tomo I7. Memoria sobre la igualdad social y política y sus relaciones con la libertad y consecuencias de la desigualdad social del hombre y la mujer. Tomo i8. Artículos sobre beneficencia y prisiones I. Tomo I9. Artículos sobre beneficencia y prisiones (contiene el artículo: Pobres mujeres) II. Tomo 20. Artículos sobre beneficencia y prisiones (contiene el artículo: Carta a un aficionado a toros y Contestación) III. Tomo 2I. Artículos sobre beneficencia y prisiones IV. Tomo 22. Artículos sobre beneficencia y prisiones (contiene artículos: Estudios sobre el trabajo de las mujeres en París y Asociaciones para la enseñanza de la mujer) V. Tomo 23. Cuadernos de la guerra.

${ }^{2}$ Ver uno de los últimos escritos publicados sobre la autora. Lacalzada de Mateo, M ${ }^{a}$ J., Concepción Arenal. El enigma de la libertad, Santander, Servicio de Publicaciones Universidad de Cantabria, 2006. En el estudio preliminar, $\mathrm{M}^{\mathrm{a}} \mathrm{J}$. Lacalzada nos recuerda que la mentalidad y proyección social que late a lo largo de toda la obra de Concepción Arenal sugiere un legado renacentista que aflora en la ilustración y zigzagueando entre liberalismos y socialismos, incluidos los llamados utópicos, palpita en el regeneracionismo al finalizar el siglo en que ella vivió.

${ }^{3}$ Cuentan los cronistas que Concepción Arenal, Emilia Pardo Bazán y Rosalía estaban emparentadas por línea materna. Concepción Arenal y Emilia Pardo Bazón eran quinta y sexta nietas, respectivamente, de Antonio Pardo de Lama Cora y Antonia Teixeiro das Inclhousas. El parentesco con Rosalía de Castro es a través de Pardo Bazán. Emilia y Rosalía son octava y séptima nietas respectivamente, de Gómez Montero y Aldarade Tobal.

${ }^{4}$ Su padre, Ángel, había apostado por el ejercicio de las libertades y no por la monarquía absoluta.
} 
Tras la muerte de su padre, Concepción Arenal, su madre y sus hermanas se instalaron en la casa solariega de Armaño para vivir allí con su abuela paterna. No abandonó Armaño hasta los catorce años cuando su madre, en I834, traslada la residencia a Madrid, sin duda para dar a sus hijas una educación y vida diferente.

Decidió estudiar Derecho en la Universidad de Madrid como alumna oyente, asistía a las clases vestida de hombre. No se sabe con certeza en qué años fue alumna, pero casi con seguridad desde 1842 hasta 1844 . Se cree que fue en la Universidad donde encontró al que luego sería su marido, Fernando García Carrasco, licenciado en leyes y de ideas liberales. Con él, ya casada, solía acudir a las tertulias literarias y políticas del Café «El Iris» de Madrid.

En Madrid, ambos esposos se ganaban la vida escribiendo artículos, especialmente para el diario La Iberia, donde él llegó a ser editorialista y redactor. ${ }^{6}$ En I857 se quedó viuda. A raíz de la muerte de su marido, se retiró con sus dos hijos a Colloto, después a Oviedo y de Oviedo a Potes (Santander).

La muerte temprana de Fernando García Carrasco, en I857, supuso un trauma afectivo y la ruptura del salvoconducto que Concepción Arenal tenía como mujer en los círculos político-intelectuales. Este período hubiera podido ser decisivo para ceder de la trayectoria liberal y refugiarse en su hogar o en actividades de beneficencia. Sin embargo, el espíritu libre de Concepción Arenal, el protagonismo que daba a la inteligencia y su potente personalidad marcaron su vida.

Desde su retiro en Potes, proyectó su pensamiento y entabló, o continuo, relaciones de amistad con los más destacados personajes de la época, conocidos por sus ideas progresistas, liberales y /o krausistas.

El premio concedido en I860 a su obra La Beneficencia, la Filantropía, la Caridad por la Academia de Ciencias Morales y Políticas supuso un pasaporte para reingresar activamente a la vida pública e intelectual del país.

En este texto, Concepción Arenal había dejado planteada la necesidad de armonizar la iniciativa del Estado que hacía «el bien sin amor» y la individual que lo hacía «sin criterio». Estaba firmemente convencida de que en la sociedad existían los elementos necesarios para consolar todos los dolores, no hay más que armonizarlos. No obstante, aceptaba la estructura del Estado liberal y la función de la Iglesia extendiendo la fraternidad en las conciencias.

En i863, Concepción Arenal es nombrada Visitadora de Prisiones de Mujeres en La Coruña, lo que la obliga a abandonar Potes para trasladarse a esta ciudad. Instalada en La Coruña empieza su original forma de desempeñar el cargo que se le había conferido,

\footnotetext{
${ }^{5} \mathrm{M}^{\mathrm{a}}$ José Lacalzada explica con nitidez la situación social y cultual del siglo XIX: «estamos en un contexto cultural en el que las ciudades crecían conservando todavía la escala humana ... Había un control social en el que existía el sentido del honor, del deber, de la responsabilidad, de la palabra dada - con la cual se podían sellar muchos contratos - y en el que la compasión no se tenía por debilidad sino por rasgo humano (...) No digo que fuesen valores socialmente dominantes sino que existían embrionariamente y se podía apelar a ellos como fuerza educadora, como signo de progreso, tanto con los de 'arriba' como con los de 'abajo'. Esta intención pesa, vertebra, da alas, a la obra de Concepción Arenal». Lacalzada de Mateo, Concepción Arenal. El enigma de la libertad, cit., pág. I8.

${ }^{6}$ La Iberia era un periódico progresista fundado por Rafael Calvo Asensio.

${ }^{7}$ El concurso lo ganó con un tema muy expresivo: «Principios que convendría seguir para enlazar la caridad privada con la beneficencia pública; hasta donde debe extender su acción el Estado, las asociaciones caritativas y las particulares y medios de poner en armonía esta acción respectiva fundándola en la economía social y en el sentimiento moral y religioso».
} 
ayudada por la Condesa de Espoz y Mina en la Coruña. ${ }^{8}$ Escribe cartas a las reclusas, eran cartas informativas de sus derechos, de los artículos del Código Penal que les afectaban, de las obligaciones que deben cumplir con arreglo a la ley, etc.

Concepción Arenal tenía muy claro un sentido integral de la reforma a emprender y comenzó a desplegar una actividad desbordante. Las huellas del absolutismo eran difíciles de borrar. Las camarillas en torno a Palacio, los pactos entre bastidores del Parlamento, las redes de los gobernadores en provincias, los pulsos librados en las políticas locales no contribuían al establecimiento de un sistema político y administrativo propio de un Estado liberal moderno. Al comenzar I863 el Gobierno se debilitaba. En I865 Concepción Arenal es cesada de su cargo como Visitadora de Prisiones.

En I868 fue nombrada inspectora de Casas de Corrección de Mujeres, cargo que ocupó hasta I873. Los tres colaboraron estrechamente con la Asociación para la Enseñanza de la mujer y fueron los fundadores de la Institución Libre de Enseñanza, una institución que buscaba desarrollar las capacidades intelectuales y las facultades morales de manera integral y activa. ${ }^{9}$

La vía de pensamiento y reforma sociojurídica en que se encuentra a Concepción Arenal sufrió en España una fuerte persecución. ${ }^{\text {Io }}$ Nuestra autora fue consciente de clamar muchas veces en el desierto, pero nunca perdió la esperanza. Y se abrió al mundo ocupando un espacio en una corriente del reformismo liberal internacional que recogía esfuerzos llegados desde diferentes posturas políticas y religiosas, unidos por el denominador común de unir ciencia y caridad -progresar en humanidad- y extenderla en las relaciones sociopolíticas. Así, fue miembro de la Sociedad General de Prisiones francesa y de la asociación Howard ${ }^{\text {II }}$ de Londres, perteneció a la Federación Abolicionista continental e intentó sin éxito establecer en España la correspondiente asociación federada. ${ }^{\text {I2 }}$

\footnotetext{
${ }^{8}$ Este cargo le permitió ver con claridad los lastres y las miserias humanas que atenazan las instituciones de Beneficencia pública desde la esfera política y de la gestión. Esta experiencia se percibe en su obra. En sus escritos, con estilo claro y directo, sacude la conciencia del lector ya sea católico, liberal, progresista o librepensador. A mi entender, el discurso de Concepción Arenal no puede considerarse ni conservador ni siquiera moderado, pues su voluntad nunca dejó de ser dinámica y posibilista.

${ }^{9}$ Este mismo año conoció a Giner de los Ríos y entablaron profundas «armonías espirituales», igual que con Gumersindo de Azcárate, personas que creían que la reforma moral en un sentido racional, natural y universal estaba en la base de las armonías en la sociedad. La estructura del Estado en la que todos ellos creían fue expresamente resumida por Gumersindo de Azcárate: Iglesia libre, Estado libre y Sociedad libre, garantizando el funcionamiento de los tres desde la esfera superior del derecho.

${ }^{\text {Io }}$ Como penalista se situaba muy cerca de la línea de pensamiento de Pedro Dorado Montero, Catedrático de Derecho Penal en Salamanca, correccionalista genuino y defensor de un Derecho penal correccional protector de los criminales, con bases positivistas. Un nuevo Derecho penal que ejercía una función tutelar, de patronato, dirigida a modificar y corregir la voluntad criminal concreta y de acuerdo con un conocimiento psicológico profundo de las causas de la criminalidad, caso a caso. De esta forma, la función penal ha de tornarse de represiva en preventiva, de punitiva en correccional, educativa y protectora. En suma, un enfoque humanitario y correccionalistas del Derecho penal, de la pena.

${ }^{\text {II }}$ Del extranjero llegaban aires de cambio. Por ejemplo, los trabajos de John Howard (I773 a I79o) autor que se reveló contra la ejecución, pensaba que era un remedio frecuente con el que afrontar los quebrantamientos de la ley. En los países mediterráneos había esclavos de la galera y el uso de la tortura para obtener confesiones de la culpabilidad era un recurso defendido por la Inquisición en España. El transporte de criminales, primero a América y más adelante a Australia, era practicado en Inglaterra. Las mazmorras estaban atestadas de deudores que no podían satisfacer sus pagos y de personas que aguardaban los juicios. Como eran conceptualizadas guaridas de la iniquidad, las prisiones de la época se caracterizaban por la humedad, oscuridad y el mal ambiente. Privadas de aire y antihigiénicas, formaban un caldo de cultivo de numerosas enfermedades. El tifus, la viruela y el bacilo de Cog fermentaban en los muros de las mismas. Había poco o nada de financiación estatal en las prisiones, pues eran costeadas con el dinero de los recluidos en las prisiones (Howard propugna una reforma al sistema penitenciario, sosteniendo que, en los establecimientos carcelarios se deberían dar las siguientes condiciones: I. cárceles higiénicas para evitar enfermedades y epidemias. 2. Separar a los condenados por delitos mayores de los condenados por delitos menores. 3. Incentivar el trabajo de los condenados en las cárceles. 4. Adopción del sistema celular, o sea, el aislamiento nocturno del condenado en una celda, de manera
} 
Concepción Arenal murió en Vigo el 4 de febrero de I893.

\section{Sus obras. Un legado histórico}

Todos los problemas humanos preocupan a Concepción Arenal, pero a ninguno prestó tanta atención como al delito, el delincuente, la pena y la forma de cumplirla, así como el análisis detallado de las prisiones y la inhumana situación de los presos, temas y problemas recurrentes a lo largo de los años, siglos: los hombres y las mujeres que han delinquido, la sociedad que desea que se le proteja de la delincuencia, las víctimas de los delitos, las respuestas de los gobiernos, las leyes de ejecución, las prisiones ${ }^{13} \mathrm{o}$, por indicar un último ejemplo, los seres humanos, las mujeres y los hombres que tienen a su cargo la aplicación de estas leyes y la administración de los reclusos.

\section{III.I. Cartas a los delincuentes}

Es una obra de envergadura, donde artículo por artículo se analiza el Código Penal para hacer comprender a los delincuentes la razón de la pena, ello de forma coloquial, explicándoles cuáles son sus derechos y la forma de defenderlos, al mimo tiempo que les da consejos y se muestra tierna con ello, o rigurosa, según los casos.

En Cartas a los delincuentes Concepción Arenal no exime nunca de responsabilidad al que comete delito. «Todos tenemos la predisposición a buscar en los escritos más bien lo que nos halaga que lo que nos instruye; todos nos inclinamos a mirar en nuestros males más bien la obra de los demás que la nuestra propia: todos prestamos fácilmente oído a quien acusa al que nos ha condenado. Esta natural propensión del hombre es más fuerte en el prisionero, que en su tristeza y tal vez en su desesperación, quiere un consuelo y una esperanza ..., tiene por artículos de fe los errores que favorecen sus inclinaciones y halla en las faltas de la sociedad, verdaderas o supuestas, una razón para sus crímenes», advertía «Desgraciada la sociedad donde las penas impuestas al violador parezcan graves, donde sea necesaria imponerlas con frecuencia, o donde siendo merecidas no se impongan!. ¡Miserable, cruel, infame mil veces el hombre que en ellas incurre!. Hay delitos sobre los que no se puede discurrir; se sienten y basta. Yo entrego a vuestro sentimiento el crimen de la violación, juzgadle los que tenéis hermanas, esposas, hijas, los que tenéis conciencia. ¿Qué digo conciencia?, los que tenéis entrañas». ${ }^{\text {I4 }}$

\section{III.2. Estudios penitenciarios}

Son muchas las veces en que Concepción Arenal responsabiliza, en parte, a la sociedad de la existencia del delincuente. «El penado no brota de una manera espontánea

que se evite la promiscuidad y la corrupción moral de los presos. 5. Establecer un sistema institucional permanente de supervisión de los recintos penitenciarios.

${ }^{12}$ Concepción Arenal fue miembro de la «Société Generale de Prisons» desde su fundación en I877. En este contexto, la autora se convirtió en una sólida referencia española, junto a Rafael Salillas o Pedro Dorado Montero.

${ }^{13}$ Las prisiones son pequeñas ciudades que reflejan, como tantas veces se ha dicho, lo que ocurre en el mundo que las circunda y las produce. Reflejan con gran viveza y dramatismo lo que es la sociedad que las circunda y las produce.

${ }^{14}$ Obras completas. Tomo 5. Estudios penitenciarios, Madrid, Tip. Huelves y Cia, pág. 324-328. 
sin tener antes del delito relaciones con la sociedad. A ella pertenecía, de ella recibía influencia, en ella tuvo complicidades, por regla general morales cuando menos; en ella encontró y ha dejado personas que no eran mejores que él, que eras peores acaso, y en fin, sin tal o cual circunstancia, que parece casual, en ella podía haber vivido, honrada o al menos pacíficamente». ${ }^{15}$

Cuando Concepción Arenal dice: «El hombre que ha delinquido es como un centro de donde parten radios a todos los problemas morales e intelectuales». ${ }^{16}$ está alertando a los poderes públicos. También los responsabiliza cuando les acusa de dictar leyes injustas, no arbitran los medios adecuados para que se puedan cumplir, no se vigila su cumplimiento, no se atienden problemas sociales acuciantes, etc. Ahí está la responsabilidad, la del resto del cuerpo social se centra principalmente en el rechazo al delincuente cuando quiere reinsertarse después de estar verdaderamente recuperado. Hay que devolver a la sociedad la confianza en el excarcelado.

Le duele nuestra autora que existan muchas personas en libertad más perversas que las que están en la cárcel. Está convencida de que la mayor parte del mal que se hace en el mundo, no lo hacen los condenados por ley, es decir, entre los que roban legalmente o sustrayéndose a la acción de la ley, los hay peores que muchos condenados por ella.

En cuanto a la pena y la forma de cumplirla, Concepción Arenal no era partidaria de la pena de muerte, que esperaba ver pronto abolida. Le molestaba la cadena perpetúa, pero la consideraba necesaria para algunos criminales si faltaba aquella. Tampoco era partidaria de las penas cortas, que no sirven más -decía- que para degradar al individuo y no para corregirle ni mejorar su personalidad, por lo que las penas debían sobrepasar, como mínimo, el tiempo de un año.

También es crítica con la prisión preventiva, su empleo sistemático le parecía funesto. Con la pena preventiva bien regulada se evitaría que muchos delincuentes se hiciesen peores, se produciría un abaratamiento de la justicia, ello en beneficio de los penados que necesitan rehabilitación, y las familias de los acusados no quedarían en la miseria.

En cuanto a la forma de cumplir la condena, una y otra vez repite que al delincuente no se le debe hacer perder su dignidad. En nuestra ley penal -aclara- se encuentra la palabra corrección y aún enmienda; pero en nuestras prisiones no hay nada propio para corregir y para enmendar. Para ella los puntos clave de una buena corrección estaban en la enseñanza y en el trabajo. ${ }^{\text {I7 }}$

${ }^{15}$ Obras completas. Tomo 5. Estudios penitenciarios I, cit., págs. I25-I26. La determinación social de la conducta, un pensamiento moderno.

${ }^{16}$ Obras completas. Tomo 5. Estudios penitenciarios I, cit., pág. I39. Hoy día, seguimos sin resolver el problema de la corrección del penado para poder reinsertarlo en la sociedad de la que salió, y no falta quien tilda a esta sociedad de responsable del delito y de poco solidaria con el delincuente cuando se le excarcela sin terminar de cumplir la pena.

${ }^{17}$ En aquella época, la mayoría de los penados no sabían leer ni escribir, por lo que proponía que la enseñanza fuese desde las primeras letras hasta una formación cultural amplia con estudios base de historia, geografía, aritmética, etc.

Detrás de estas opiniones se pueden encontrar las reflexiones y buenas prácticas del Coronel D. Manuel Montesinos y Molina. «Bases en que se apoya mi sistema penal sin las que serán, no sólo inútiles, sino perjudiciales cuantos medios se intenten para morigerar nuestro criminales (...) Inspirar en el alma del delincuente sentimientos de unidad y de afición al trabajo, encaminándolos a útiles ocupaciones, debe ser el objeto moral de sus ocupaciones, debe ser el objeto moral de las Penitenciarias públicas, para que desde ellas no salgan a precipitarse de nuevo a la carrera interminable de los delitos.

Perfeccionar al hombre es hacerlo más sociable, todo lo que tienda a destruir su sociabilidad, impedirá su mejoramiento.

Por esto, las penas, lejos de atacar deben favorecer este principio, fomentando su acrecentamiento (...) 
Concepción Arenal, caritativa pero rigurosa, considera que la pena ha de huir de toda crueldad y aún de toda dureza, pero ha de ser severa y firme. Y argumenta que las medidas más eficaces contra el delito son las preventivas, las que evitan que se consuma combatiendo la miseria, la ignorancia, y ofreciendo apoyo, en vez de mal ejemplo, a los que vacilan y están en peligro de caer. trabajo. ${ }^{\mathrm{I}}$

Para ella los puntos clave de una buena corrección estaban en la enseñanza y en el

Y ya para terminar este breve repaso por algunos puntos de las obras de Concepción Arenal, destacar que para la autora la clave de un buen sistema penitenciario correccional está en los funcionarios que han de aplicarlo. Lo primero que exige de estos es moralidad. Además de moralidad, exige para los funcionarios una formación especial. Y lo afirma porque está firmemente convencida de que si se han de corregir los delincuentes, es preciso formar un cuerpo verdaderamente facultativo, con conocimientos especiales, adecuados al difícil objeto que se proponen.

\section{A modo de conclusión}

Concepción Arenal ilumina el siglo XIX español. Su pensamiento, enraizado en la Ilustración y en las filtraciones del doctrinarismo francés, se fue alimentando de las más

El sistema que algunos defienden, de absoluto aislamiento, debe considerarse como muy imperfecto, porque sólo satisface a una de las condiciones de la pena, cual es la mortificación de aquellos; por esto no ha producido los resultados que se esperaban.

La incomunicación absoluta y perpetua adoptada como pena, es un principio seguro de desmoralización, porque su necesario término será siempre la locura o suicidio». «Testamento penitenciario de Montesinos», Boletín de Información Penitenciaria, núm. 2, pág. I6.

${ }^{18}$ El fin de resocialización de las penas propicia la humanización de las cárceles, la responsabilidad individual y social de ese proceso intercomunicativo que constituye la integración social y fundamentalmente, evita que la pena en su fase de ejecución se convierta en un mero castigo, con clara predominio del fin retributivo.

Pero, precisamente en los momentos en que se consagraba legalmente y se establecía la orientación de la política penitenciaria del país encaminada hacia el fin resocializador.

Se empezó a hablar de la crisis de la resocialización, sus limitaciones para grupos importantes de delincuentes como los delincuentes ocasionales, los delincuentes por convicción y los delincuentes socioeconómicos, se llamó la atención sobre la imposibilidad de llevarla a cabo por medio de la prisión, sobre la necesidad de utilizar grandes recursos del Estado para hacerla efectiva, cuestión difícil de solventar en momentos de crisis del Estado de Bienestar y por consiguiente, retraimiento del gasto público, etc.

La preocupación por los derechos fundamentales de los presos en general es un fenómeno relativamente reciente, pues data de la década de los setenta, en que se promulgaron leyes penitenciarias modernas (Italia, Alemania, Francia) y deberes, orientando todo el fin de la reclusión a la resocialización del delincuente (art. I LGP). La propia constitución también se hace eco del ideal resocializador en el artículo 25.2 y manda que la ejecución penal de la pena privativa de libertad esté presidida por este principio.

Hoy, se puede decir que después del encanto resocializador vivido durante los años setenta y comienzos de los ochenta, asistimos a etapa real de retraimiento del fin de la resocialización para el cumplimiento de penas. La praxis de asesinatos cometidos por sujetos que gozaban de permisos de salida, la magnificación de la inseguridad ciudadana por ciertos medios de comunicación, el aumento de la violencia terrorista de los últimos tiempos, han propiciado un retraimiento real de la orientación resocializadora de la pena. Esto se ha hecho patente con las limitaciones de los permisos de salida, la eliminación de la redención de penas por el trabajo, aumento del cumplimiento efectivo de las penas, etc.

Indudablemente, existen muchas limitaciones para llevar a cabo el proceso reinsertador del recluso en la cárcel y quizás es importante conectarlo con dos momentos fundamentales: antes y después del cumplimiento, esto es, buscar remover y contrarrestar la marginación social y la violencia que la delincuencia conlleva, así como brindar al ex recluso una seria asistencia postpenitenciaria. Pero lo que sí prácticamente todos los autores están de acuerdo es que mientras exista cárcel, ésta debe tender a por lo menos hacer el encierro un proceso lo menos desocializante posible, buscando evitar el desarraigo social y familiar, haciendo que la preparación para la vida en libertad sea un objetivo fundamental con el objeto de conseguir que el recluso no recaiga en el delito al salir de la prisión. 
diversas tendencias internacionales del reformismo liberal. La coherencia intelectual de Concepción Arenal es muy profunda. Existen principios que no varían a lo largo de su vida: la confianza en la Razón, la búsqueda de una moral natural y activa, la sensibilidad humanitaria. Estas actitudes de conocimiento y comportamiento se fueron contrastando mientras se materializaba la revolución liberal en España.

La sobra del legado de esta mujer permanece aún vigente. Concepción Arenal traspasó los límites de los cercos carcelarios para horrorizarse y horripilar mostrando la miseria y desgracias allí reunidas y presentando un programa de acción, pragmático, utópico y realista a la vez.

Concepción Arenal es una figura nacional e internacional. Asombra como encerrada en los estrechos límites de unas provincias norteñas pudiese, por un lado, estar relacionada así como establecer amistades duraderas con altas personalidades españolas de la época y, por otro, que su nombre traspasase nuestras fronteras siendo sus obras objeto de estudio por hombres sabios en materia penitenciaria y se le proclamara autoridad europea en la materia. ${ }^{\text {I9 }}$

Mujer original y con un poderoso sentido común. Dijo muchas verdades limpias y claras, que a veces hay que buscar dentro de largos párrafos, donde parece que las envolvía para no escandalizar.

\section{Bibliografía}

ÁlVAREz URÍA, F. y Varela, J., Sujetos frágiles. Ensayos de sociología de la desviación, Madrid, Fondo de Cultura Económica, I989.

ANTÓN ONECA, J., «La teoría de la pena en los correccionalistas españoles», en VV.AA., Estudios jurídico-sociales. Homenaje al profesor Luis Legaz Lacambra, II, Santiago, Universidad de Santiago de Compostela, ig6o.

ARENAL, C., Obras completas, Madrid, Librería de Victoriano Suárez, I894.

ARNAZ, E., Cultura y prisión: una experiencia y un proyecto de acción sociocultural penitenciaria, Madrid, Popular, I988.

BARATTA, A., Criminologia critica e critica del diritto penale (trad. castellana de H. Alemán, Criminología crítica y crítica del Derecho penal, México, Siglo XXI, I986, por donde se cita).

- Criminologia critica e critica del diritto penale. Introduzione alla sociología giuridico-penale, Bolonia, II Mulino, I982 (trad. castellana de Álvaro Bunster, Criminología crítica y crítica del derecho penal, México, Siglo XXI Ed., I986).

BARBERET, R., «La investigación criminológica y la política criminal», en E. Larrauri (ed.), Política Criminal, Cuadernos de derecho judicial, Madrid, Madrid, Consejo General del Poder Judicial, I999, págs. 43-69.

BeCCARIA, C., Dei delitti e delle pene, i764 (trad. castellana de J. A. de las Casas, De los Delitos $y$ de las Penas, Madrid, Alianza Editorial, $3^{a}$ ed., I982, por donde se cita).

19 La Asociación Howard, de Londres, la nombró miembro de la misma. Anéctoda curiosa es que la confundieron de sexo. Algunas de sus obras fueron traducidas al inglés y al francés. En esta lengua, antes que en español, apareció publicado su libro El visitador del preso, escrito en i89ı. 
Bentham, J., Panopticum: or the inspection house, I79I (trad. castellana El Panóptico, Madrid, La Piqueta, I989, $2^{a}$ ed., por donde se cita).

Bergalli, R., Bustos, J. y Miralles, M., El pensamiento criminológico, Barcelona, Península, I982.

Bustos, J. y LARRAURI, E., Victimología: presente y futuro. Hacia un sistema penal de alternativas, Barcelona, Promociones y Publicaciones Universitarias, I993.

CAnguilhem, G., Le normal et le pathologique, París, Presses Universitaires de France, ig66 (trad. castellana de Ricardo Potschart, Lo normal y lo patológico, México, Siglo XXI Ed., I97I).

CAPIlla PÉReZ, A., «Concepción Arenal: un enfoque desde el trabajo social», Portularia; Revista de Trabajo social, Vol. I, 200I, págs. I55-I70.

Carmena, M., Prólogo, en C. Arenal, El visitador del preso, Madrid, Asociación de Colaboradores con las Presas, I99I.

Chistie, N., La industria del control del delito, Buenos Aires, Editores del Puerto, I993.

Cid Moliné, J., «El sistema de penas desde una perspectiva reduccionista: alternativas a la pena de prisión», en E. Larrauri (ed.), Política Criminal, Cuadernos de derecho judicial, Madrid, Consejo General del Poder Judicial, I999, págs. I2I-I48.

Cid Moliné, J. y Larrauri Pijoan, E. (eds.), Penas Alternativas a la Prisión, Barcelona, Bosch, I997.

Clemmer, D., «The Prison Community», Boston, Christopher Ed., I940. Una edición posterior: Nueva York, Rinehart and Co. Ed. I958.

CoHen, S., Visions of Social Control, Cambridge, Polity Press, I985 (trad. castellana de E. Larrauri, Visiones de control social, Barcelona, P.P.U., I988).

CueStA ARZAMENDI, J.L., «Presente y futuro de las instituciones penitenciarias españolas», Eguzkilore, extra de enero, I988, págs. II5-I28.

DAHRENDORF, R. (i988): The Modern Social Conflict (trad. castellana de F. Ortiz, El conflicto social moderno, Madrid, Mondadori Ed., I990).

DíAZ CASTAÑón, C., «Concepción Arenal en su centenario», Revista de Occidente, núm. I5I, págs. I37-I52, I993.

FoucaulT, M., Sourveiller et punir. Naissance de la prison, I975 (trad. castellana de A. Garzón, Vigilar y Castigar, Madrid, Siglo XXI, Io. ed., I984, por donde se cita).

García Pablos de Molina, A., Tratado de criminología, Valencia, Tirant lo blanch, 2.. ed., I999.

GARRIDo GENOVÉS, V., «El tratamiento penitenciario en la encrucijada», en Revista de Estudios Penitenciarios, núm. 236, I986, págs. 2I-3I.

Garrido Genovés, V., Stangeland, P. y Redondo Illescas, S., Principios de Criminología, Valencia, Tirant lo blanch, I999.

JIMÉNEZ-SAlinAS, E., «Spain», en D. Van Zyl Smit, y F. Dünkel (eds.), Imprisonment Today and Tomorrow. International Perspectives on Prisoner's Rights and Prison Conditions, 
Berlín, Kluwer, ı99ı.

Goffman, E., Asylums, Nueva York, Anchor Books, I96I (trad. castellana Internados, Buenos Aires, Amorrortu, I970).

Hulsman, L. Y Bernat De Celis, J., Peines perdues, I982 (trad. castellana, Sistema penal y seguridad ciudadana: Hacia una alternativa, Barcelona, Ariel, I984, por donde se cita).

Kropotkine, P., Las Prisiones», Barcelona-Palma de Mallorca, Pequeña Biblioteca Calamus Scriptorius Ed., I977.

Lacalzada de Mateo, M.J., Concepción Arenal. El enigma de la libertad, Santander, Servicio de Publicaciones de la Universidad de Cantabria, 2006.

— «El reo, el pueblo y la justicia. Reflexiones a partir de Concepción Arenal», Revista de Servicios sociales y política social, núm. 29, I993, págs. 73-85.

— «Las coordenadas político-intelectuales de Concepción Arenal». Revista Sistema, núm. II6, I993, págs. II9-132.

LAMO DE ESPINOSA, E., «Delitos sin víctima. Orden social y ambivalencia moral», Madrid, Alianza Ed., I989.

Larrauri Pijoan, E., La Herencia de la Criminología Crítica, Madrid, Siglo XXI, 3. ed., I99I, 2000 .

— «Criminología crítica: abolicionismo y garantismo», Nueva doctrina Penal, I998, págs. 719-753.

Malinowski, B., Crime and Custom in Savage Society, Londres, Routledge \& Kegan Ed., I926 (trad. Castellana, Crimen y costumbre en la sociedad salvaje, Barcelona, Ariel Ed., I956).

MAPELLI, B., «Desviación social y resocialización», Cuadernos de política criminal, núm. 22, págs. 3II-388, I984.

MARISTANy, L., El gabinete del doctor Lombroso. Delincuencia y fin de siglo en España, Barcelona, Cuadernos Anagrama Ed., I973.

MAtZA, D., Becoming Deviant, Englewood Cliffs, NJ., Prentice Hall, I969 (trad. castellana de J. Carabaña, El proceso de desviación, Madrid, Taurus ed, I98I).

Melossi, D. y PaVARInI, M., Carcere e fabbrica. Alle origini del sistema penitenziario. XVI-XIX, Florencia, II Mulino Ed., I977, (trad. castellana de X. Massimi, Cárcel y fábrica. Los orígenes del sistema penitenciario (siglos XVI-XIX), México, Siglo XXI Ed., I980.

MORRIS, N., The Future of Imprisonment. Studies in Crime and Justice, Universidad de Chicago Ed., I974 (trad. castellana de Nicolás Grab, El futuro, México, Siglo XXI Ed., I978.

MUÑOZ CONDE, F., «La resocialización del delincuente: análisis y crítica de un mito», Revista Sistema, núm. 3I, I979, págs. 73-84.

Neuman, E. y otros, La sociedad carcelaria, Buenos Aires, Depalma Ed., I974.

PinATEL, J., La société criminogène, París, Calmann-Lévy Ed., I97I (trad. castellana de Luis Rodríguez Ramos, La sociedad criminógena, Madrid, Aguilar Ed., I979). 
QUinNEY, R., «Control del crimen en la sociedad capitalista: una filosofía crítica del orden legal», en I. Taylor, P. Walton y J. Young (eds.), Criminología Crítica, México, Siglo XXI, I977.

SAlinAS, R., Inspiradores de doña Concepción Arenal, Madrid, Editorial Reus. (Documento en la Biblioteca de la Facultad de Derecho de la Universidad de Castilla-La Mancha, Albacete), I920.

TAYlor, L., WAlton, P. y Young, J., Critical Criminology, Londres, Routledge \& Kegan Paul Ltd. Ed., I975 (trad. castellana de N. Grab, Criminología Crítica, México, Siglo XXI Ed., I977).

Telo Núñez, M., Concepción Arenal y Victoria Kent. Las prisiones. Vida y obra, Madrid, Instituto de la Mujer, I995.

Turk, A., Criminality and Legal Order, Chicago, Rand McNally and Co. Ed., I969.

VAlverde Molina, J., El proceso de inadaptación social, Madrid, Ed. Popular, I988. 